\title{
FORUM MARITIM KUNCI SUKSES PENANGGULANGAN ANCAMAN ASIMETRIS DI SELAT SUNDA
}

\author{
Suhirwan ${ }^{1)}$ dan Lukman Yudho Prakoso ${ }^{2)}$ \\ 1)Prodi Peperangan Asismetris, Fak. Strategi Pertahanan \\ Universitas Pertahanan, Bogor \\ suhirwan@gmail.com, \\ 2)Prodi Strategi Pertahanan Laut, Fak. Strategi Pertahanan \\ Universitas Pertahanan, Bogor \\ lukman.prakoso@idu.ac.id
}

\begin{abstract}
Abstrak
Penelitian di Selat Sunda ini dilakukan karena posisinya yang sangat dekat dengan Kota Jakarta yaitu Ibu Kota Negara Republik Indonesia sehingga memiliki eskalasi potensi ancaman yang sangat tinggi dihadapkan dengan potensi ancaman pertahanan negara yang mungkin terjadi di Selat Sunda jika tidak diantisipasi. Angka kejahatan lintas Negara di Indonesia dari tahun ketahun selalu naik tajam, tertangkapnya penyelundupan narkoba di perairan Banten sejumlah 1 (satu) ton pada tahun 2017, sangat jelas bahwa Jakarta sudah menjadi sasaran asymmetric Warfare. Dengan mempertimbangkan hal tersebut maka: "Bagaimanakah sinergitas kelembagaan bidang kemaritiman dalam pelaksanaan tugas pokoknya dalam menghadapi ancaman asimetris warfare di Selat Sunda Propinsi Banten?" Penelitian ini menggunakan metode penelitian kualitatif diskriptif fenomenologi dengan pembahasan menggunakan teori sinergitas. Nara sumber yang dilibatkan sebagai informan adalah semua penegak hukum di laut dan pihak terkait. Memperhatikan data-data hasil wawancara kepada Narasumber, bahwa terdapat sinergitas di dalam pelaksanaan tugas pokok dan fungsi masing-masing kelembagaan bidang kemaritiman, walaupun masih berjalan sendiri-sendiri, hal ini dapat dibuktikan dengan tidak adanya pertukaran informasi, sehingga satu dengan lainnya saling mencari informasi sendiri-sendiri. Dltemukan faktor pendukung berupa telah adanya forum antara penegak hukum maupun dengan pemerintah daerah setempat, namun juga ditemukan kendala yang utama yaitu terbatasnya anggaran dalam menunjang kegiatan operasi dan terbatasnya pendukung sarana/prasarana yang diperlukan. Selain itu masih ditemukan juga kendala sharing informasi antara penegak hukum. Sebagai penutup hasil penelitian ini dapat disimpulkan bahwa diperlukan forumforum maritim resmi dan tidak resmi yang dapat mempertemukan para stake holder untuk saling bertukar informasi yang dapat dimanfaatkan untuk kepentingan menanggulangi asimetrik warfare di Selat Sunda sesuai dengan potensi bidang tugas dan fungsi masing-masing. Forum-forum ini untuk menghilangkan faktor-faktor penghambat sinergitas dalam implementasi kebijakan pertahanan dengan adanya kepentingan dan penafsiran yang berbeda dalam hal pelaksanaannya. Perbedaan penafsiran ini diakibatkan adanya perbedaan struktur organisasi masing-masing implementor.
\end{abstract}

Kata Kunci: Sinergitas, Banten, Komunikasi, Organisasi, Kejahatan Lintas Negara.

\begin{abstract}
The research in the Sunda Strait was carried out because its position which is very close to the City of Jakarta, the State Capital of the Republic of Indonesia so that it has a very high escalation of potential threats faced with the potential threat of national defense that may occur in the Sunda Strait if it is not anticipated. Transnational crime rates in Indonesia from year to year have always risen sharply, the capture of drug smuggling in Banten waters in the amount of 1 (one) ton in 2017, it is very clear that Jakarta has been the target of asymmetric warfare. Taking this into account: "What is the synergy of maritime institutions in carrying out their main tasks in the face of the asymmetrical warfare threat in the Sunda Strait of Banten Province?" This research uses descriptive phenomenological qualitative research methods with a discussion using the theory of synergy. The resource persons involved as informants were all law enforcers at sea and related parties. Paying attention to the interview data to the resource person, that there is a synergy in the implementation of the main tasks and functions of each institution in the maritime sector, although it is still running on its own, this can be proven in the absence of information exchange, so that one another looks for information individually. Found a supporting factor in the form of the existence of a forum between law enforcement and the local government, but also found the main obstacles namely the limited budget to support operational
\end{abstract}


activities and the limited support of facilities / infrastructure needed. In addition, there are also obstacles to information sharing between law enforcement. To conclude the results of this study, it can be concluded that official and unofficial maritime forums are needed which can bring together stakeholders to exchange information that can be used for the benefit of overcoming asymmetric warfare in the Sunda Strait in accordance with the potential of their respective task fields and functions. These forums are to eliminate the inhibiting factors of synergy in the implementation of defense policies with different interests and interpretations in terms of their implementation. The difference in interpretation is due to differences in the organizational structure of each implementor.

Keywords: Synergy, Banten, Communication, Organization, Transnational Crime.

\section{PENDAHULUAN}

\section{Umum}

Posisi silang Negara Kesatuan Republik Indonesia (NKRI) yang berada diantara dua benua Asia dan Australia serta dua Lautan Pasifik dan Hindia, menempatkan NKRI pada posisi strategis. Indonesia sebagai negara kepulauan yang memiliki wilayah laut sangat luas memiliki keuntungan memiliki sumber daya alam yang sangat luar biasa, juga potensi ancaman yang besar, potensi ancaman di laut Indonesia adalah satu diantara lima ancaman terbesar Indonesia saat ini, seperti yang disampaikan oleh Marsekal TNI Hadi saat melaksanakan tes kelayakan sebagai Panglima TNI. Konsekuensi memiliki wilayah laut yang luas, negara harus dapat melindungi wilayah tersebut dari ancaman faktual maupun yang sifatnya potensial, Marsekal TNI Hadi selanjutnya mengatakan bahwa: "Kerawanan di laut sebagai negara kepulauan, Indonesia bertanggungjawab atas keselamatan dan keamanan di wilayah laut yang menjadi yurisdiksinya termasuk pada laut-laut bebas yang berbatasan langsung dengan wilayah tersebut" (Tjahyanto, 2017).

Wilayah Laut Indonesia tidak saja memiliki arti penting bagi Indonesia, juga memiliki arti yang sangat penting untuk dunia internasional, karena wilayah laut Indonesia terletak di posisi silang dunia yang sering dilewati transportasi laut negara-negara lain. Salah satu konsukuensi pengakuan dunia terhadap Indonesia sebagai negara kepulauan, Indonesia harus membuat dan menetapkan beberapa lajur Internasional yang melewati wilayah yuridiksi nasional Indonesia untuk dapat digunakan berbagai negara untuk melintas di wilayah laut Indonesia.
Dampak lain terhadap kepadatan lalu lintas pelayaran di Selat Malaka, seperti digunakannya wilayah ALKI I oleh perompak untuk menghindari kejaran aparat keamanan Indonesia dan aparat keamanan gabungan (Indonesia, Malaysia, dan Singapura) atau penyelundupan. Imbas dari pusat pertumbuhan dan perekonomian Asia dan Asia Tenggara di Republik Rakyat Cina (RRC) dan Singapura, seperti penyelundupan barang-barang ilegal dan juga perdagangan manusia, turut menjadi potensi ancaman di ALKI I, termasuk imbas bahaya ancaman bencana alam dan tsunami di Selat Sunda, seperti ancaman gempa vulkanik/erupsi gunung berapi (anak Krakatau) dan imbas politik ekspansional Malaysia, seperti kemungkinan klaim wilayah teritorial baru.

Ancaman lain secara faktual dan potensial sangat tinggi adalah Kejahatan Lintas Negara yang Terorganisasi (Transnational Oraganised Crime), dari tahun ke tahun, angka kejahatan lintas negara di Indonesia mengalami peningkatan. Pada tahun 2010 terjadi 10.444 kejahatan, meningkat di tahun 2011 menjadi 16.138 kasus, kemudian di tahun 2012 sejumlah 21.457 kasus, tahun 2013 sejumlah 34513 kasus, tahun 2014 sejumlah 34.513 kasus, tahun 2015 sejumlah 40.938 kasus, dan tahun 2016 sejumlah 41.033 kasus. Jumlah kejahatan transnasional yang ditangani Polri mengalami peningkatan. Penyelundupan narkotika dari luar negeri ke Indonesia merupakan kejahatan transnasional yang paling menonjol. Jenis kejahatan lain adalah terorisme, trafficking, kejahatan dunia maya, dan penyelundupan manusia. (Pradopo, 2013)

Ancaman faktual yang terjadi pada bulan Juli 2017 menggemparkan wilayah Selat Sunda yaitu ditangkapnya penyelundupan 
sabu-sabu 1 (satu) Ton diperairan Banten. Kabid Humas Polda Metro Jaya Kombes Raden Prabowo Argo Yuwono mengatakan, "polisi juga menangkap tiga tersangka dalam operasi penyelundupan 1 ton sabu tersebut. Satu orang tewas ditembak petugas lantaran berusaha melawan". Selanjutnya Argo mengatakan, bahwa: "Jadi total ada 51 karung. Sabu diperkirakan ada seberat 1 ton. Tapi jumlah pastinya belum dihitung" (Deslatama, 2017)

Ini menunjukkan keberadaan akses masuk perairan wilayah laut Indonesia masih sangat rawan dan sangat berpotensi terjadinya ancaman asimetrik warfare, jika saja sabu-sabu tersebut tidak tertangkap dapat membunuh lima juta jiwa menurut Kepala BNN (Badan Narkotika Nasional) Budi Waseso (Hadi Maulana, Kompas.com). Setelah kejadian tersebut berturut-turut berhasil ditangkap kembali penyelundupan melalui jalur laut dalam jumlah Ton. "Berbagai hal tersebut pada gilirannya telah menjadikan fungsi utama angkatan perang sebagai peran konvensional menjadi obsolete (usang) jika dibandingkan dengan ancaman kontemporer lainnya yang bersifat asimetris, proksi, hibrida, dan kejahatan lintas negara termasuk siber," (Tjahyanto, 2017).

Dalam penelitian ini, tempat penelitian yang diambil adalah di Selat Sunda. Salah satu alasan terkuat untuk mengambil tempat penelitian di Selat Sunda ini adalah, posisi yang sangat dekat dengan lbu Kota Negara sehingga memiliki eskalasi potensi ancaman yang sangat tinggi, jika terkait potensi ancaman pertahanan yang mungkin terjadi di Selat Sunda tidak diantisipasi. Kebijakan tentang pertahanan negara telah dibuat oleh Kementerian Pertahanan $\mathrm{Rl}$ untuk melindungi segenap bangsa, namun dianggap penting untuk selalu waspada dengan tidak henti-hentinya melakukan penelitian terhadap bagaimana implementasi kebijakan pertahanan ini dilaksanakan khususnya pada lokasi-lokasi yang memiliki tingkat potensi paling tinggi.

\section{Rumusan Permasalahan}

Dari pembahasan pada latar belakang maka rumusan permasalahan dapatlah di sampaikan sebagai berikut: Bagaimanakah sinergitas kelembagaan bidang kemaritiman dalam pelaksanaan tugas pokoknya dalam menghadapi ancaman asimetris warfare di wilayah perairan Selat Sunda Propinsi Banten?

\section{METODE PENELITIAN}

Pembahasan penelitian ini menggunakan metode kualitatif diskriptif, pembahasan melalui kerangka teori sinergitas. Konsep sinergitas ada karena kebutuhan untuk membangun masyarakat atas dasar kerjasama yang saling menguntungkan dan dilandasi pemikiran- pemikiran yang rasional, terbuka, dan demokratis.

Dalam Konsep sinergitas menurut Slamet Mulyana dalam tulisannya sinergitas dan kemitraan perencanaan program Bentuk dari sinergitas yakni: (Mulyana, 2008):

1. Koordinasi, Dalam koordinasi tersebut perlu ditetapkan hubungan antara stakeholder terkait apakah bersifat hubungan vertical, hubungan horizontal, komando, koordinasi maupun hubungan kemitraan, dan

2. Komunikasi, Dalam komunikasi pertukaran informasi antara dua orang atau lebih yang juga meliputi pertukaran informasi antara pihak satu dengan pihak yang lain.

\section{HASIL DAN PEMBAHASAN}

Sinergitas yang diharapkan disini akan tercipta sebuah keadaan yang saling sinergi dalam keamanan di laut untuk mencegah terjadinya pelanggaran dan menciptakan keamanan di laut. Pelaksanaan tugas bidang keamanan di wilayah laut perairan Selat Sunda Propinsi Banten ini, untuk mengaplikasikan sistem pertahanan laut dalam satu kesatuan, sehingga mampu menciptakan tata kelola sistem pertahanan yang baik. Untuk mewujudkan pelaksanaan tugas tersebut, maka terdapat faktor-faktor yang harus dapat bersinergi antara stake holder bidang kemaritiman dengan baik dan dioptimalkan fungsinya sehingga wilayah laut dapat terhindar dari ancaman faktual yang berbentuk asimetrik warfare.

Panglima TNI Marsekal TNI Hadi Tjahyanto pada kesempatan pemberian penghargaan kepada Tim Western Fleet Quick Response (WFQR) Lantamal IV 
Tanjungpinang, Badan Narkotika Nasional, Polda Kepri dan Bea Cukai Batam, atas kekompakan dalam kerja samanya yang berhasil mengungkap kasus besar ini, menyatakan, bahwa: "Saya harap sinergitas TNI, Kepolisian, BNN dan Bea Cukai bisa terus terjaga, agar ke depan kita bisa melakukan pengungkapan kasus-kasus besar lainnya, tidak saja narkoba, ancaman keamanan negara juga bisa kita minimalisir bersama," (Maulana, 2018). Demikian juga pernyataan: Kepala BNN Komisaris Jenderal Budi Waseso mengatakan, bahwa: "ke depan pihaknya akan terus berkoordinasi dengan stakeholder terkait dalam pemberantasan narkoba di Indonesia, khususnya di wilayah perairan". Selanjutnya Budi, mengatakan, "Kami sadar saat ini jaringan sindikat narkoba internasional 85 persen menggunakan jalur laut, makanya kami akan terus berkoordinasi dengan TNI $\mathrm{AL}$ dan Bea Cukai dalam penindakan di laut, Kami tidak mau hal ini terjadi dan melalui sinergitas ini bersama TNI AL, Polri, dan Bea Cukai kami bisa memberantas perdagangan gelap narkoba ini," (Maulana, 2018)

Sinergitas stake holder disini adalah suatu kegiatan gabungan atau kerja sama lebih dari dua lembaga atau organisasi yang berbeda untuk memberikan hasil yang lebih baik, kegiatan yang dilakukan tersebut adalah untuk pelaksanaan tugas pokok sesuai dengan fungsi masing-masing guna menunjang suatu situasi keamanan wilayah laut di perairan Banten. Hal ini selaras dengan pernyataan Kapolda Banten, Kapolda berharap kepada Ditpolair Polda Banten dapat terus semangat dan berbenah untuk tetap mempertahankan keamanan di Selat Sunda Perairan Banten. "Agar perairan Banten dapat terjaga, untuk itu segala kejahatan laut diharapkan dapat ditangani dengan tegas. Ditpolair Polda Banten harus mampu mengawal sehingga seluruh apa yang menjadi program pemerintah kita bisa amankan," ujarnya. (Kabar Banten, 2017)

Pelaksanaan tugas pokok dan fungsi ini untuk menunjang pertahanan negara di laut secara menyeluruh. Pelaksanaan sinergi bidang keamanan laut di perairan Banten dilakukan dengan memperhatikan, sebagai berikut:

1. Peningkatan kerjasama antara stake holder bidang kemaritiman dengan ujung tombak TNI AL.
2. Pelaksanaan tatacara integrasi tugastugas stake holder dalam satu satuan tugas yang terkoordinasi

3. Pemanfaatan jejaring komunikasi yang terinteroperabilitas sebagai fungsi komando guna memperlancar pelaksanaan tugas pokok dan fungsi masing-masing stake holder.

4. Pelaksanaan sistem evaluasi pada setiap akhir penugasan sebagai sarana guna memperbaiki dan peningkatan tugas berikutnya.

Berdasarkan data-data hasil wawancara penelitian kepada Narasumber dalam pelaksanaan tugas menghadapi asimetrik warfare, bahwa: terdapat Standar Operating Procedure (SOP) masing-masing stake holder bidang kemaritim sesuai dengan bidang tugas pokok dan tanggung jawab masing-masingnya, namun masih perlu penyamaan persepsi bersama sehingga pelaksanaannya dapat terlaksana dengan baik. Penerapan SOP yang sudah ada selama ini dilaksanakan sebagai bagian dari standar dalam pelaksanaan tugas, sehingga anggota di lapangan dapat mengetahui tugas pokoknya untuk apa dan berbuat apa. Konsep pelaksanaan tugas pokok dan fungsi masing-masing stake holder bidang kelautan di perairan Selat Sunda Propinsi Banten sudah dilaksanakan cukup baik sesuai dengan SOP yang ada. Para stake holder sudah melaksanakan tugas pokok dan fungsinya untuk menciptakan suatu situasi keamanan sehingga tidak terjadi tindak pelanggaran. Peran masing-masing sesuai dengan tugas dan fungsinya yang dijabarkan di dalam petunjuk pelaksanaan tersebut serta diadakan pengawasan, pembagian peran untuk tugas-tugas internal dan eksternal dilaksanakan secara berjenjang.

Data-data hasil wawancara kepada Narasumber dalam sinergitas pelaksanaan tugas dan fungsi masing-masing stake holder, bahwa sudah terdapat sinergitas di dalam pelaksanaan tugas pokok dan tanggungjawab masing-masing implementor bidang kemaritiman, walaupun masih berjalan sendiri-sendiri, hal ini dapat dibuktikan dengan tidak adanya pertukaran informasi, sehingga satu dengan lainnya saling mencari informasi sendiri-sendiri. Diperlukan forum-forum resmi gabungan yang dapat mempertemukan para 
implementor untuk saling bertukar informasi yang dapat dimanfaatkan untuk kepentingan menanggulangi asimetrik warfare di Selat Sunda sesuai dengan potensi bidang tugas dan fungsi masing-masing.

Terdapat beberapa faktor pendukung dalam pelaksanaan tugas dan fungsi tersebut, antara lain:

1. Adanya updating data sesuai dengan perkembangan dinamika pelaksanaan tugas di lapangan serta diadakan evaluasi dan pengawasan.

2. Adanya pendukung dalam konsistensi yang dilaksanakan melalui forum-forum formal dan non formal dan dirumuskan dalam kebijakan untuk dijadikan pedoman serta penggunaan media sosial dalam sosialisasinya.

3. Adanya dukungan dalam bidang informasi dan tata kelola pelabuhan berupa dukungan informasi dari masingmasing stake holder.

4. Terdapat koordinasi dan kerjasama diantara implementor bidang kemaritiman dengan memahami setiap tugas dan tanggungjawabnya masingmasing.

Terdapat juga beberapa faktor kendala dalam pelaksanaan tugas dan fungsi tersebut, antara lain:

1. Kekurangan dan ketidak seimbangan dukungan anggaran dalam pelaksanaan tugas dan fungsinya masing-masing stake holder dibandingkan dengan banyaknya kegiatan yang harus dilaksanakan.

2. Kendala Jumlah ideal sarana dan prasarana yang seharusnya ada dibandingkan dengan luas wilayah yang harus dilaksanakan pengawasan.

3. Kendala pelaksanaan sinergitas dilapangan sering tidak berjalan dengan mana semestinya, dikarenakan perbedaan struktur organisasi berdasarkan kewilayahan ataupun area pengawasan, terkadang masing masing implementor mempunyai interest dan penafsiran yang berbeda dalam pelaksanaan tugas dan fungsinya.

Berdasarkan data-data hasil penelitian bidang sinergitas/hubungan antara satu satuan kerja dengan berbagai satuan kerja yang lain, wawancara kepada Narasumber dalam menghadapi asimetrik warfare, bahwa terdapat sinergitas antara implementorimplementor bidang maritim. Kegiatan ini ditunjukan dengan koordinasi dan komunikasi yang baik antara masing-masing implementor sehingga tidak terjadi benturan kepentingan di lapangan. Masih diperlukan forum resmi maupun tidak resmi untuk sharing informasi sesuai tugas dan fungsinya masing-masing, sehingga pelaksanaan tugas dan fungsi masing-masing dapat terlaksana untuk menjaga wilayah perairan di Selat Sunda Propinsi Banten.

\section{KESIMPULAN}

Sinergitas stake holder bidang kemaritiman dalam pelaksanaan tugas pokok dan fungsinya masing-masing sudah dapat dilaksanaan sesuai dengan SOP, namun demikian masih terdapat faktor-faktor penghambat, antara lain:

1. Koordinasi

a. Untuk keberhasilan pelaksanaan implementasi tugas pokok dan fungsi masing-masing stake holder pada saat pelaksanaannya di lapangan telah dilaksanakan saling berkoordinasi sesuai dengan bidang tugas dan fungsinya masingmasing.

b. Pelaksanaan koordinasi dari implementasi ini adalah dengan berpedoman kepada peraturanperaturan tertulis dan petunjukpetunjuk lisan, agar pelaksanaan tugas pokok dan fungsinya dapat terlaksana dengan baik.

2. Komunikasi

a. Sinergitas antara satu satuan kerja dengan berbagai satuan kerja yang lain, adalah belum adanya sinergitas yang optimal, dikarenakan pelaksanaan kebijakan pertahanan masih berjalan sendiri-sendiri, sehingga belum adanya sharing informasi yang dilaksanakan, perolehan informasi didapat secara sendiri-sendiri. Mengingat pentingnya informasi dalam pelaksanaan tugas dan fungsi kebijakan pertahanan diperlukan suatu forum bersama yang digunakan sebagai tempat berkumpul implementor dalam hal 
bertukar informasi untuk melaksanakan tugas pada masingmasing implementor.

b. Membangun sistem dan jaringan komunikasi yang terinteoperabilitas, sehingga para stake holder bidang kemaritiman dapat terhubung dalam satu kesatuan komunikasi yang terpusat.

Adanya koordinasi dan komunikasi dalam melaksanakan tugas dan fungsinya masingmasing stake holder merupakan wujud dukungan terhadap pelaksanaan sinergitas diantara satu satuan. Pelaksanaan tugas pokok dan fungsinya ini dibutuhkan sharing informasi dalam suatu forum resmi merupakan implementasi dari pelaksanaan komunikasi dan koordinasi. Oleh sebab itu, dalam pelaksanaan sinergitas stake holder bidang kelautan agar dilakukan secara berkala komunikasi dan koordinasi dalam forum-forum formal dan non-formal, sebagai wadah untuk sharing informasi. Forum-forum ini untuk menghilangkan faktor-faktor penghambat sinergitas dalam implementasi kebijakan pertahanan dengan adanya kepentingan dan penafsiran yang berbeda dalam hal pelaksanaannya. Perbedaan penafsiran ini diakibatkan adanya perbedaan struktur organisasi masing-masing implementor.

\section{UCAPAN TERIMA KASIH}

Terima kasih dan penghargaan yang tinggi kepada Komandan Lanal Banten beserta jajaran stake holder bidang kemaritim di wilayah Banten yang telah mengijin dan berpartisipasi dalam penelitian ini.

\section{DAFTAR PUSTAKA}

Burhan, B. (2012). Metode penelitian kualitatif. Jakarta: PT Raja Grafindo Persada.

Creswell, J. W. (2014) research design: pendekatan kualitatif, kuantitatif, dan mixed. Yogyakarta: Pustaka Pelajar.
Darwanto, H. (2015, Desember 26). Perang asimetris untuk hancurkan nasionalisme dan ideologi. Diakses dari http://www.indocropcircles.wordpress.com

Deslatama, Y.(2017, Juli 13). Sabu 1 ton diselundupkan ke Banten via jalur laut Diakses dari https://www.liputan6.com/

Direktorat Jenderal Strategi Pertahanan. (2008). Perkembangan lingkungan strategis dan prediksi ancaman tahun 2008. Diakses dari http://www.kemhan.go.id/

Kabar Banten. (2017). Kapolda Banten: tindak tegas kejahatan laut. Diakses dari https://www.kabarbanten.com/author/k_ba nten/

Kecskemeti, P. (1958). Strategic surrender: The politics of victory and defeat. London: Oxford University Press.

Kementerian Pertahanan Republik Indonesia. (2015). Buku Putih Pertahanan Indonesia. Diakses dari http://www.kemhan.go.id/

Kementerian Pertahanan Republik Indonesia. (2017). Pertajam analisa perkembangan lingkungan strategis, Kemhan bentuk Badan Informasi Strategis Pertahanan. Diakses dari http://www.kemhan.go.id/

Liputan 6. (2011). Panglima TNI: BIN-BAIS tak akan bertabrakan. Diakses dari https://www.liputan6.com/

Maulana, H. (2018, Februari 12). Temuan 1 ton sabu selamatkan 5 juta jiwa, Panglima TNI beri apresiasi. Diakses dari https://regional.kompas.com/

Moleong, L. J. (2014). Metodologi penelitian kualitatif. Bandung: PT. Remaja Rosdakarya.

Mulyana, I. (2007). Sinergi: Style of management.

Pradopo, T. (2013, January 14). Kejahatan transnasional meningkat penyelesaian secara hukum menjadi pekerjaan rumah. Diakses dari http://news.liputan6.com/

Pranoto, M. A. (2015, April 16). Mengenal perang asimetris: Sifat, bentuk, pola dan sumbernya. [Facebook]

Poros Berita. 2016. Kemhan jamin Badan Intelijen Kemhan beda dengan BIN dan BAIS.

Rahmawati, T., Noor, I., \& Wanusmawatie, I. (2017). Sinergita stake holders dalam inovasi daerah: Studi pada program seminggu di Kota Probolinggo (SEMIPRO). Jurnal Administrasi Publik (JAP), 2(4), 641-647. 
Reksoprodjo, Y. (2016, Oktober 1). Perang asimetrik Menwa UI. Diakses dari http://www.scribd.com/document/3261179 15/perang-asimetrik-menwaui-011016-cpdf

Sofyandi, H. dan Garniwa, I. (2007). Perilaku organisasional. Yogyakarta: Graha IImu.

Tjahyanto, H. (2017, Desember 6). Ini 5 potensi ancaman bagi Indonesia menurut Marsekal Hadi. Diakses dari http://nasional.republika.co.id/ 
Suhirwan \& Prakoso / Forum Maritim Kunci Sukses Penanggulangan Ancaman ... 